\title{
Hybridization in Economic Activities in Samuel Selvon's The Lonely Londoners and Moses Ascending
}

\author{
Tingxuan Liu \\ Faculty of Foreign Languages \\ Huaiyin Institute of Technology \\ Huai'an, China
}

\begin{abstract}
Samuel Selvon (1923-1994) is a pioneer in Caribbean literature. His Moses trilogy is very representative because of his preoccupation with issues of culture and identity. This paper attempts to employ Homi Bhabha's theory of hybridity to illustrate the Creoles' struggle against colonization and the construction of economic hybridity. From the perspective of economic, The Lonely Londoners and Moses Ascending deal with the fractured and disjointed economic activities on the Londoners and Moses' economic life, covering from general economic life to personal economic behavior. The hybridization of economic activities helps Creoles walk out of the tough period and be able to support themselves. It is an effective way for them to be free from colonization economically.
\end{abstract}

Keywords-Samuel Selvon; The Lonely Londoners; Moses Ascending; hybridization

\section{INTRODUCTION}

In 1994, Homi Bhabha put forwards the famous theory of Hybridity in his book The Location of Culture (1994). From his point of view, it is inadequate to use center or margin to define the relationship between the colonists and the colonized because they are mutually exclusive and depend on each other. He notes that "Hybridity is the sign of the productivity of colonial power, its shifting forces and fixities; it is the name for the strategic reversal of the process of domination through disavowal..." (Bhabha, 1994:159) Bhabha defines hybridity as "the name of this displacement of value from symbol to sign that causes the dominant discourse to split along the axis of its power to be representative, authoritative." (Bhabha, 1994:159) And he stresses on the ambivalence of hybridity. It is not a third term to settle down the tension between two cultures. Homi Bhabha's theory of Hybridity is an important tool to conduct his postcolonial criticism, widely applied in some English texts featured in the postcolonial characteristics like works of Conrad and Naipaul. Hybridity adapts to this global trend. It can help colonized countries rebuild their culture. Nowadays, the theory of Hybridity has more and more realistic significance especially for those ethnic groups. They still keep in touch with their cultural tradition but have to adapt in their new residential culture. The theory of Hybridity can make us pay more attention to the conflict and exchange of different cultures in the context of globalization.
The process of Creoles' economic hybridization can be divided into two phases. The first phase is the phase of attachment. That is to attach to capitalist economy. When the Creoles first settle down in London in the 1950s, they face an extremely severe challenge of living. They have no business, no funds, without any form of finance to support. And all of them face the same dilemma. They can't help each other. They have to stay in the bottom, being engaged in physical work because of their low degree of education and the language barriers. But after they live through the toughest period, their life is improved a lot and they quickly transit into the next stage - the stage of imitation and learning. That is the phase of being hybridized. During this period, they have some funds after their everyday expense. They learn how to consume from the Londoners and some of them begin to own some properties and become the capitalist class, beginning to make money like those capitalist Londoners. Some people of them even realize that culture could bring wealth and move towards the industry of culture, gradually melting in their main stream of economic life.

While the vast majority of The Lonely Londoners deals with the fractured and disjointed experiences on the London streets, the novel closes with some prolonged attention to the much smaller, much more stable, and space of Moses' economic life. The shift in focus from the macro to the micro also reveals a shift from general economic life to personal economic behavior. This shift also reveals the subtle change of hybridization.

\section{HYBRIDIZATION IN ECONOMIC ACTIVITIES}

\section{A. Phase of Dependency - The Lonely Londoners}

The severe economic environment is the major reason for them to be in the phase of attachment. Early in The Lonely Londoners, Selvon himself makes a seemingly obvious designation when he says that "every man on his own" (Selvon, 1985: 21). It is also a substitution of "Londoners" for the Creoles. More importantly, the fear of survival, in the shadow of the real Londoners, is more notable. Without any pre-existent support network, the boys know that the search for work is simultaneously a search for a framework to govern their lives. If the role of breadwinner is their major role in society, then the job that wins that bread determines his place in the London society. Money determines where a 
man lives, what he eats, where he goes, and whom he knows. When they first come to London, they don't have money. They live in some sort of anxiety. Selvon directly recognizes this anxiety in the long passage about the welfare office in The Lonely Londoners when the narrator says:

A job is all the security a man have... When a man out of work he like a fish out of water grasping for breath. It have some men, if they lose their job it like the world end, and when two-three weeks go by and they still ain't working they get so desperate they would do anything. (Selvon, 1985: 29)

A job is the necessary condition for survival; it makes an inhabitable environment all by itself. In such a context, the welfare office is actually a place where loads the prospect of salvation and the specter of financial and psychological insolvency:

it ain't have no place in the world that exactly like a place where a lot of men get together to look for work and draw money from the welfare state while they ain't working. Is a kind of place where hate and disgust and avarice and malice and sympathy and sorrow and pity all mix up... A place where everyone is your enemy and your friend. (Selvon, 1985: 29)

The British working class has an ambiguous attitude towards these people. They fear the immigrants will get job in front of them. The men working in the welfare office are, it seems, too vulnerable to feel generous. They have common hardships that they tend to view each other as competitors in a contest that is essentially a life and death struggle. There is also an uneasy but recognizable sense of communal feeling between the boys and the English working class, which accounts for the hybrid mixture of sympathy, sorrow, and pity with disgust, avarice, and malice. But the British people are experiencing a tough time with them together. Because of the Second World War, the economy of most capitalist country has been injured. London is during its receding-economy period. There are not many job vacancies but there are a great many job demands. During this period, the work they have found is at night for that most white people are not willing to be on night duty. They even could not tell the fact they are immigrates before the job interview, or they may not even get the chance to have an interview. These people help each other; they introduce the job opportunity to each other because they have to depend on each other during this tough time. They have also imagined the life when they have money. But they don't seem to have the awareness of spending money like Londoners. Their life is confined in their circle. Moses has once said "I was still ready to go back home. I used to go by them shipping offices and find out what ships leaving for Trinidad, just in case I happen to raise the money ..." (Selvon, 1985: 129) they don't blend into London society. Even they have lived in here for a long time; they are thinking about making money and leave for home rather than spending money like Londoners.

The second reason for the phase of attachment is that it is not mature for any individual to develop economic activities independently. An individual's power is too small. They have to unite to reinforce their financial basis. So there is a unique character formed naturally in Creole circle - whenever a newcomer comes to London from their hometown, the age-old Creole in London will go to the wharf to pick him up and lead him to adapt to the London life. Moses is a kind of this role. When Galahad first comes to London, he picks him up and does some introduction. He also offers a lot of help to him. When they finish every week's work, the boys come to Moses's place for their Sunday gatherings. It is actually a "retreat ... into the narrow confines of ... home". (McCulloch, 1983: 127) But Galahad is not a fellar that has the obedience to follow him. He tries very hard to make Moses feel that he is a strong man who can take good care of himself. But after some time he spends in London, he slowly finds it is not easy to live in London. When Galahad first dates a white girl in London, the heavy pressure of sex and money are resolved not in terms of what he feels, but in terms of what he thinks his public expects. Obsessively aware of his social status and personal property he has difficulty prioritizing the material dimension of his identity. His feeling of "shame to bring the girl in that old basement room" (Selvon, 1985: 76) must be overcome because "the boys would never finish giving him tone for spending all that money and not eating". (Selvon, 1985: 76) Lack of money is the major reason contributing to the form of a community. They have to pay for the rent and food; they have to make a living. All the money they get from work is used up for everyday life. They don't have money to entertain themselves. After work, they can only gather together and have nowhere to go except their living place. When they go into Moses' room, they find a shelter where they can escape from an exhausting world. It becomes its own micro society with its own multiplicity of relations, duties, and possibilities. Here in Moses' room, they find a sense of belonging which they can only find in their own circle because they don't belong to the London society. Even they live in here, they work here and they work for them or with them, they don't get their status in London. They are only attached to the society. Indeed, Samuel Selvon suggests that Moses' dirty room is like a "church", (Selvon, 1985:122) he imposes a ritualistic kind of spirituality onto their scattered, frequently vacuous, lives. In many special ways, the Creoles are seeking escape and salvation in their gatherings. They come to unburden themselves, to confess the week's trials. More than anything else, their failure is redeemed and is transformed into another form of positive thing. When they could not satisfy themselves with materials, they can only have mental support. Thus, the Creoles find their greatest comforts by emphasizing the emotional over the material, the private motivation over the public directive, and the local narrative over the global trope. The condition of the shallow space seems to lower the significance of material and property but reinforce their friendship and community. Far away from London society, they find a subtle form of wealth that is based on their individual needs and hopes rather than any kind of wealth. Through that, they feel successful and powerful and even achieve a measure of personal satisfaction.

\section{B. The Hybridized Economic Activities - Moses Ascending}

After the Creole immigrants experience the toughest period in London, everything begins to turn good. Most of 
them have some capital and properties and begin to learn how to consume or how to deal with money from those Londoners. They begin to launch a series of hybridized economic activities. "Selvon's satirical look at black home ownership, landlordism, and memoir writing provides his revised - but still politically attuned - 1970s view of the London of migrants' everyday lives”. (Dyer, 2002: 113)

First of all, the hybridized economic activities are reflected in the male immigrants' relationship with females during this period. In London, they have the feeling that "loins are useless". (Gilmore, 1990: 42) When Bart suffers a variety of humiliations from the girl he loves, he feels that "he has failed at being a man". (Gilmore, 1990: 42) London is a city where money is the dominant measure of significance and worth, even the sexual relationships. Sexual relationship is built up on money. Moses and his friends have been reduced to what they describe as "liming" and "coasting" in London public parks for sex with ladies of the night. They do despise the women as much as they need them. Without money, they are not able to develop any relationship with them. Evidently, "money dominates even the most intimate relations in the city, making it impossible to form any long-term relationships for any immigrant. Even if they begin, it is rather difficult for them to keep it because the stress is too heavy." (Msiska, 2009: 18) But when these immigrants have gathered a sum of money, they could not only watch or imagine or just show they have no interests, they begin to build their sexual relationship. But they could afford those London girls. They are more willing to build relationships with the prostitutes especially the white ones. This kind of relationship is in fact a relationship of employment. Only at these moments, they feel that they are not the employee but the employer.

The second typical case during this economic-hybridized period is the shift in economic relationship among these immigrants in Moses Ascending. Samuel Selvon chooses Moses as the center role because he lives in London for a long time and seems to adapt to the London society more than his fellows. What's more, he has taken part in a lot of economic activities and changed his pattern of economic behavior. His change for the most part reflects the economic hybridization. The first thing he does is to buy a big house.

Nevertheless Galahad didn't know one arse about houses: it's true some of these terraces in London look like they might capsize any minute, but united we stand, divided we fall, and knowing Tolroy as I do, it stand to reason that he would not of bought no end-of-terrace house, but one plunk in the middle what would have support on both sides. (Selvon, 2008: 2)

When Moses shows his interests in the house, his original social status hasn't changed. His personal relationships with his old Creole fellows haven't fallen apart as well. During that period, he still thinks the community of their fellows is important, which affects their survival and living condition in the big city like London. This is the typical colonial economy. They are exploited and squeezed in their local place by the colonial power. They have to depend on themselves. They must combine. And they have no capitals or opportunities to get away from the control and to become independent. Leaving from their poor hometown and living in London gives them this opportunity. They watch and learn as well as gather capitals. Moses is a guy of that pattern. After working hard so many years in London, his efforts have been paid off. His mind begins to change, too. $\mathrm{He}$ begins a new pattern of making money like local Londoners.

"If you let out rooms you can make you money back in no time at all. Besides, you will be a landlord and not a tenant." It was this latter point which decided me in the end. After all these years paying rent, I had the ambition to own my own property in London, no matter how ruinous or dilapidated it was. If you are a tenant, you catch your arse forever, but if you are a landlord, it is a horse of a different color. (Selvon, 2008: 2)

After that, Moses stops looking for jobs. Ever since, he makes a living by renting rooms. He becomes a landlord. Most of his tenants are immigrants from poor countries. He then has the initiative in economic activities. Therefore, we can foresee that after he gets the initiative, Moses thinks shifts in financial and social status should happen in corresponding as well as in personal relationships. When he becomes a homeowner and landlord, he becomes preoccupied with his station in life and attempts to enforce a "parting of the ways" between himself and his former fellows. He begins to give up those personal relationships because he thinks they are of no more use to him. Instead, he opts for public affairs. We can define that his awareness of self-consciousness is arising. He realizes that he can depend on himself and gets away from the former small community. Ever since that, he has melted into the economic environment of London society. He begins to get far away from his former circle. They gradually vanish from Moses' life and become part of his memory.

Moses has lost most of his relationship with his former fellows. His relationship with people around him begins to change into some kind of economic relationship. Former friends come to visit him for money not for friendship any more. The first one who comes to him is Galahad. In Moses Ascending, he becomes a crazy fan for political and racial movement. He is some kind of leader in this organization. They fight for justice, independent and equality, which Moses doesn't show any interests in. He only cares about how to make money and how to blend into this society quickly. But their political movement is in need of money. They need to find a financial support. So Galahad finds Moses. At this time, their friendship is gone. They haven't talked about any old times. Galahad wants desperately the financial support from Moses. But Moses enjoys this kind of feeling. He achieves great kind of joy and satisfaction from this. Not surprisingly, the only relationship Moses has in his life is economic relationship. However, he enjoys this feeling.

I cannot tell you what joy and satisfaction I had the day I move into these new quarters. Whereas I did have a worm's eye view of life, I now had a bird's eye view. I was Master of the house. I insert my key in the front door lock, I enter, I ascend the stairs, and when the tenants hear my heavy tread 
they cower and shrink in their rooms, in case I snap my fingers and say OUT to any of them. (Selvon, 2008: 5)

In this paragraph, Selvon uses a lot of "I" to show that the self-consciousness of Moses begins to sprout after he has economic foundation. His "self-consciousness undermines the masculine assertion". (Schwenger, 1984: 14) The economic relationship between his tenants and him becomes the most important relationship in his life. From then on, his thoughts shift in financial and social status. He begins to pursue for "public visibility". (Hearn, 1992: 3)

Thirdly, the economic relationship between the immigrants and the white people has begun to change, which is also important during the economic hybridization. Their economic relationship is not traditional. The whites' monopoly position in economy has broken up. The shifts in economic relationship that occurs in the passage from The Lonely Londoners to Moses Ascending, are located in the surface shifts in his relation to the ordered economy. Moses makes Bob, his white servant and tenant to serve for him as a way to pay the bill, which facilitates Moses' entry to ordered economy by making him an employer, which also keeps him in the subversive relation to the immigrants including Moses, Galahad and even Brenda. Thus, Moses finds that his greatest comforts by emphasizing the material over the emotional, the public direction over the private motivation and the global trope over the local circle. Bob doesn't have money to pay the rent. Then things develop in another new direction. Bob takes his girlfriend, Jeannie, another white girl to Moses' house and lives. From these analyses we know that the significant change in the immigrants. Like Moses, or there might be some other immigrants who have broke down the old economic relationship and become the dominant people in an economic relationship. We also find that in London, some white people even live a more tough life than the immigrants. The reason lies in that they are probably illiterate or they are too lazy to work for money. And from Moses and his black companions we believe that once they work hard, they can afford themself a good life.

There is also a fourth aspect of economic hybridization. That is their step into the cultural industry. Samuel Selvon doesn't write much in this aspect because it is just sprouting and is in its rudiment. From Moses Ascending, we are informed of the fact that black people have their own literature. They have powerful writers to write powerful books. Moses is an example. He is fond of writing his Memoirs. At first, he only writes for fun. But then he treats writing as a job and thinks himself as a writer. He begins to live a kind of life he could not expect before. He thinks he is a writer and that is a job that is exclusive to white people. And of this job, he employs himself. This belongs to another kind of economic relationship. Then he realizes that when he finishes his Memoirs, he can print them to sell. And this has two advantages: first is that they can make the white world notice them, knowing their existence and struggle; second is that he can make money through this. This small step in cultural industry is a big step in economic hybridization. The shortcoming is that they are not well educated before. To develop their own cultural industry, there is still a long way to go.

\section{CONCLUSION}

The Trinidian people in the postcolonial age full of bright hope come to London, "the epic trajectory of Selvon's London", (Ingrams, 2001: 34) trying to find the cohesion between different nations, which is expressed in "exile, Black oppression, British racism, capitalist exploitation and so on". (Brown, 1996: 35) The interactive impact finds its extreme expression in aspects of economy as well as in politics. This kind of hybridization may be more notable and direct because economic problems have a close relationship with people's survival condition. The preoccupation with money and work that pervade Selvon's work is indicative of the depth and the degree to which his characters feel the imperative toward capital as an imperative toward self, the degree to which money, work, life have become inextricably linked. Despite the fact that Selvon describes these people as "a bunch of lazy loafers", they are actually a group of economic-affairs-obsessed people, constantly concerning about jobs, work conditions and the wage that come with them. Their economic behaviors are gradually hybridized in a subtle way. From The Lonely Londoners to Moses Ascending, during the period of almost 30 years, their life style has changed remarkably. The hybridization of economic activities is more notable and direct because economic problems have a close relationship with people's survival condition. And the hybridization of economic activities is more than significant for their struggle for decolonization. The importance of economic hybridization lies in that the economic activity is the most fundamental among all kinds of activities. Their living conditions all depend on them. Once they settle their economic life, they can even start their political life or cultural pursuit.

The hybridization of economic activities has great meanings. First of all, they get used to the London society and London lifestyle, and they begin to make money like the local Londoners. When they first come to London, they have nothing. They have no house to live in. they have no job. They have no money to spend. They have to live in a small community, depending on each other. One single person's power is too small. They have to be united. But after they have adapted to London society, they begin to learn from them on economic aspects. They learn how to make money through doing business. At the beginning, it is rather difficult for them. Because there are a lot of local people in want of making a living where there are not so many job vacancies compared with them, they are less educated and don't have any skills. They have to compete with the local people to find a job. They work with the local people. And gradually they have blended in the London society and their economic activities become a part of the whole economic activities. They are, to some extent, fostering the recovery of London economy. They keep doing some kind of low-paid jobs that the local residents are unwilling to do. They do most of the duties on night. They become the essential part of the London labor.

The second aspect is that they begin to have capitals and become capitalists. They begin to have their own industry. Some of them launch a shop, selling something or offering some service; some of them buy a big house and become a 
landlord; some of them even pay the white people to work for them. These changes show that the old economic relationship between white people and the immigrants has collapsed. The former economic relationship is very single but now it becomes complicated. In the past, the black people are always the employed while the white people are always the employers. The white people are always the shipowners, landlords and labor contractors while the black people are always clerks, tenants, and workers. The immigrants are not always been employed and the white people are not always the employers. The economic relationship has changed definitely.

The third aspect is that some of the immigrants start to set foot in cultural industry. Black people have the awareness of raising their cultural level. They also have the awareness that culture is a form of wealth, which could bring money. They are no longer confined to the labor work. Writing and selling memoir is only a beginning. From then on, they may emphasize the effects of education more and more. The white people will notice them and pay attention to them. Maybe one day, they will have their own cultural industry. Stepping into the cultural industry is the most important example of economic hybridization, which may never happen in their hometown. They have not even imagined this in the past days in their hometown. The background of London endorses the Creoles this.

The immigrants have made achievement in economic hybridization. They have changed the single economic pattern and made it more complex. They have brought new vigor to the economic atmosphere of London. At the same time, the hybridization of economic activities does well to the immigrants, too. It helps them walk out of the tough period and be able to support themselves. It teaches them to learn new pattern of living. However, they just begin their journey and there is a long way to go.

\section{REFERENCES}

[1] Bhabha, Homi K. The Location of Culture. London: Routledge, 1994.

[2] Brown, Wayne. "'A Greatness and a vastness' The Search for God in the Fiction of Sam Selvon". Ariel: A Review of International English Literature. Calgary: University of Calgary, 27(2), 1996:35-46.

[3] Dyer, Rebecca. "Immigration, Postwar London, and the Politics of Everyday Life in Sam Selvon's Fiction". Cultural Critique. Minneapolis: University of Minnesota Press, 52, 2002: 108-144.

[4] Gilmore, David. Manhood in the Making: Cultural Concepts of Masculinity. New Haven: Yale UP, 1990.

[5] Hearn, Jeff. Men in the Public Eye: The Construction and Deconstruction of Public Men and Public Patriarchies. London: Routledge, 1992.

[6] Ingrams, Elizabeth. "The Lonely Londoner: Sam Selvon and the Literary Heritage". Wasafiri, London: Routledge, 16(33), 2001:33-36.

[7] McCulloch, Jock. Black Soul, White Artefact: Fanon's Clinical Psychology and Social Theory. Cambridge: Cambridge UP, 1983.

[8] Msiska, Mpalive-Hangson. "Sam Selvon's The Lonely Londoners and the structure of Black metropolitan life". African and Black Diaspora: An International Journal. London: Routledge, 2(1), 2009: 5-27.

[9] Schwenger, Peter. Phallic Critiques: Masculinity and TwentiethCentury Literature. London: Routeledge \& Kegan Paul, 1984.

[10] Selvon, Samuel. The Lonely Londoners. Essex: Longman, 1985.
[11] Selvon, Samuel. Moses Ascending. London: the Penguin Group, 2008. 